\title{
Immune thrombocytopenic purpura among the children attending at two teaching hospitals
}

\author{
Md. Golam Hafiz ${ }^{1}$, M A Mannan ${ }^{1}$, Syed Khairul Amin², Afiqul Islam ${ }^{1}$ and Fazlur Rahman ${ }^{3}$ \\ ${ }^{1}$ Department of Pediatric Hematology and Oncology, Bangabandhu Sheikh Mujib Medical University, Shahbag, \\ Dhaka; ${ }^{2}$ Department of Pediatric Medicine, Bangladesh Institute of Child Health, Dhaka; ${ }^{3}$ Department of \\ Cardiology, Bangabandhu Sheikh Mujib Medical University, Shahbag, Dhaka, Bangladesh.
}

\begin{abstract}
The presenting features, diagnostic evaluation, seasonal variation and management performed in 110 children with immune thrombocytopenic purpura (ITP) attending at two tertiary level hospitals were evaluated. A peak incidence of children with ITP was observed during the month of June, July and the first step was found in May and lowest in the month of October to December. Mean initial platelet count was $65.5 \times 10^{9} / \mathrm{L}$. 35 patients with ITP did not require any treatment who were kept under observation and the rest 75 children who were admitted to hospital given platelet count enhancing treatment- intravenous immunoglobulin in 9, corticosteroids in 60 or both in 6 children with ITP. Intracranial hemorrhages were noticed in two children with ITP. So, this study suggests that ITP had special predilection during summer season and the least in winter along with variable approaches to management of these children.
\end{abstract}

\section{Introduction}

Immune thrombocytopenic purpura (ITP) is a common pediatric hemotologic disorder ${ }^{1}$. ITP in children is generally a short, self-limiting illness with a good prognosis. It has an equal sex incidence and usually occurs in children aged 2 to 10 years, often after a viral infection. In a typical case, the child is well but has a dramatic presentation with widespread cutaneous purpura, sometimes accompanied by mucosal hemorrhages and epistaxis; however, the child recovers quickly without serious morbidity. Despite this good outlook, fierce debate over the management of these children continues $^{1-3}$. ITP is a syndrome characterized by thrombocytopenia (platelet count $<100,000 / \mathrm{mm}^{3}$ ), shortened platelet survival, presence of anti-platelet antibody in the plasma and increased megakaryocytes in the bone marrow ${ }^{4}$. ITP in children is typically a benign self limiting condition, is one of the most common hematologic disorders encountered by the practicing physicians ${ }^{5,6}$. The term ITP has been loosely applied to four conditions: post viral thrombocytopenia, "true" idiopathic thrombocytopenia in which no precipitating factor or associated illness can be found, thrombocytopenia associated with other autoimmune syndromes and drug-induced immune thrombocytopenia ${ }^{7}$.

The typical patient ${ }^{6,8-10}$ is a healthy younger, who recently has a non-specific viral infection. The alarmed parents bring their child to a pediatrician, who observes that findings on physical examination are quite normal except for the bleeding manifestations. The complete blood count is also normal except for marked thrombocytopenia ${ }^{6}$. The management of children with ITP is based primarily on expert judgment and the local practice guidelines rather than on the evidence based and has been the subject of furious contention for decades. Although practice guidelines have been developed and put into circulation ${ }^{11,12}$, but the compliance with the guidelines is not satisfactory $^{13,14}$ and the validity of one set of guidelines has been openly demand ${ }^{3}$.

A shared agreement protocols and trials for malignant diseases does exist but not for this benign condition. The lack of evidence based approach is inconvenient for patients with dissimilar medical and socioeconomic influences, reflected by the array of simple and subtle 
diagnostic procedures and treatment, from no therapy to multiple costly platelet increasing agents with various untoward effects ${ }^{15,16}$. The natural history of the disease has been narrated in several retrospective studies $^{12}$. However, a prospective record has only been earned from randomized clinical examinations with short follow-up and fairly small number of patients.

Till now, to the best of our knowledge, there is no such study on ITP among the children in our country, but it is proposed by many workers in different situations that ITP has got different treatment approach, geographical and seasonal variation.

With this background, we aimed to make a coordination of pediatrician of BSMMU and $\mathrm{BICH}$ to involve in the diagnosis and management of children with ITP, to prospectively collect the clinical records regarding the natural history and the outcome of children with ITP.

\section{Materials and Methods}

This prospective study was carried out in 110 diagnosed case of ITP of both sexes, age ranged from 1 to 15 years in the Pediatric Hematology and Oncology, Department of Pediatrics, Bangabandhu Sheikh Mujib Medical University (BSMMU) and Department of Pediatric Medicine, Bangladesh Institute of Child Health (BICH), Dhaka, Bangladesh over a period of 4 year from January 2004 to December 2007.

Each patient with diagnosed case of ITP seen at a participating center was included for registration. However, the participation was willingly and therefore it is assumed that not each successive patient was registered. Eight pediatricians from two teaching hospitals enlisted the patients by completing and submitting an entry sheet. A questionnaire was requested the address of the pediatrician and record from the patient including date of birth, sex, date of diagnosis, platelet count at diagnosis, whether a bone marrow aspirate had been done, whether the patient had been admitted to hospital and whether treatment (intravenous immunoglobulin, corticosteroids or both) had been given or not. The record sheet was presented as soon as possible after the diagnosis of ITP patients to the coordinating center at Pediatric Hematology and Oncology, BSMMU, Dhaka, Bangladesh.

After 6 month, the coordination center fixed another questionnaire to each pediatrician to obtain a follow-up data, when it was possible to distinguish acute from chronic form of ITP, defined by a persistence of thrombocytopenia $(<150 \mathrm{x}$
$10^{9} / \mathrm{L}$ ) for 6 month or longer. This questionnaire addressed the follow up platelet count every two weeks interval initially then monthly and finalized whether the patient had bleeding manifestation during 6 month period, whether intracranial hemorrhage (ICH) had occurred or not and whether the patient had received additional platelet count increasing treatment or not (intravenous immunoglobulin, corticosteroids, or both) during first 6 months.

Confirmation of ITP was based on the platelet count of less than $100 \times 10^{9} / \mathrm{L}$ (estimated by hematologist using Sysmex XS 800i Automated Hematology Analyzer, Japan) at the Department of Pediatrics, BSMMU and $\mathrm{BICH}$, a normal hemoglobin concentration, white blood cell count and blood smear (except for thrombocytopenia) and the absence of underlying diseases ${ }^{4}$. Blood sample of each respective patient was send to both participating hospitals for manually re-check of platelet count estimation so that inter observer variations were minimized. Bone marrow aspiration was not mandatory. The main purpose of performing a bone marrow examination was to exclude the other hematological disorders, such as leukemia.

As the data of the patients in this study were from different teaching hospitals, we have stratified the patients in two groups as per hospitals. Additionally, the varying number of patients from two hospitals makes the interpretation of the statistical analysis troublesome but still we have organized the data into a statistical format. All the continuous data were expressed as mean \pm SD and the categorical data in percentage. Therefore, the results were represented in a descriptive manner without any statistical analysis.

\section{Results}

Age group less than 1, 1-5 and more than 5 years there were 9, 62 and 39 children with ITP respectively.

Mean \pm SD of age in all enlisted children was $5.7 \pm$ 4.1 years. Mean \pm SD of age in boys and girls was $(5.9 \pm 4.4)$ years and $(6.4 \pm 4.7)$ years respectively.

ITP was diagnosed with a peak incidence in the month of June and July and a nadir in the month of October to December (Figure 1).

Mean platelet count of all children with ITP at initial presentation was $65.5 \times 10^{9} / \mathrm{L}$. At 6 month mean platelet count was $180.8 \times 10^{9} / \mathrm{L}$. Chronic ITP was seen in $27 \%$ of children with equal numbers of girls and boys. Mean age was 7.2 years 
with chronic ITP and 5.8 years with acute ITP. Aged less than 1, 1-5 or older than 5 years there were $3 \%, 31 \%$ and $66 \%$ respectively had chronic ITP. Chronic ITP had a mean platelet count at initial diagnosis was $75.5 \times 10^{9} / \mathrm{L}$ and those with acute ITP was $55.0 \times 10^{9} / \mathrm{L} .110$ children with ITP for whom records were in hand on treatment, 35 (31.82\%) patients did not receive any drug treatment and 75 (68.18\%) patients received treatment, either with IVIG, corticosteroids or IVIG plus corticosteroids (Table I). 4 children received either IVIG or corticosteroids or both despite an initial platelet count of more than $65 \times 10^{9} / \mathrm{L}$.

Children who received or not received initial drug treatment at diagnosis was in acute ITP 69\% and $31 \%$ respectively and in chronic ITP 56\% and 44\% respectively. IVIG was given in children with acute
ITP 56\% and in children with chronic ITP $44 \%$. Corticosterods were administered in children with acute ITP 58\% and in children with chronic ITP $42 \%$.

Platelet count of more than $150 \times 10^{9} / \mathrm{L}$ at 6 months was achieved in $71.4 \%$ of untreated children and $28.6 \%$ of children treated with different modalities. Two children out of 110 with ITP developed ICH for whom 6-month follow-up records were submitted. One child of 2 year old girl in whom an $\mathrm{ICH}$ developed at 3 months after the diagnosis of ITP with a favorable outcome without any neurological sequelae. Another patient was 9 years old girl with initial platelet counts of $42.6 \times 10^{9} / \mathrm{L}$ and treated initially with corticosteroid. The time when ICH developed and the consequence of this child was not known.

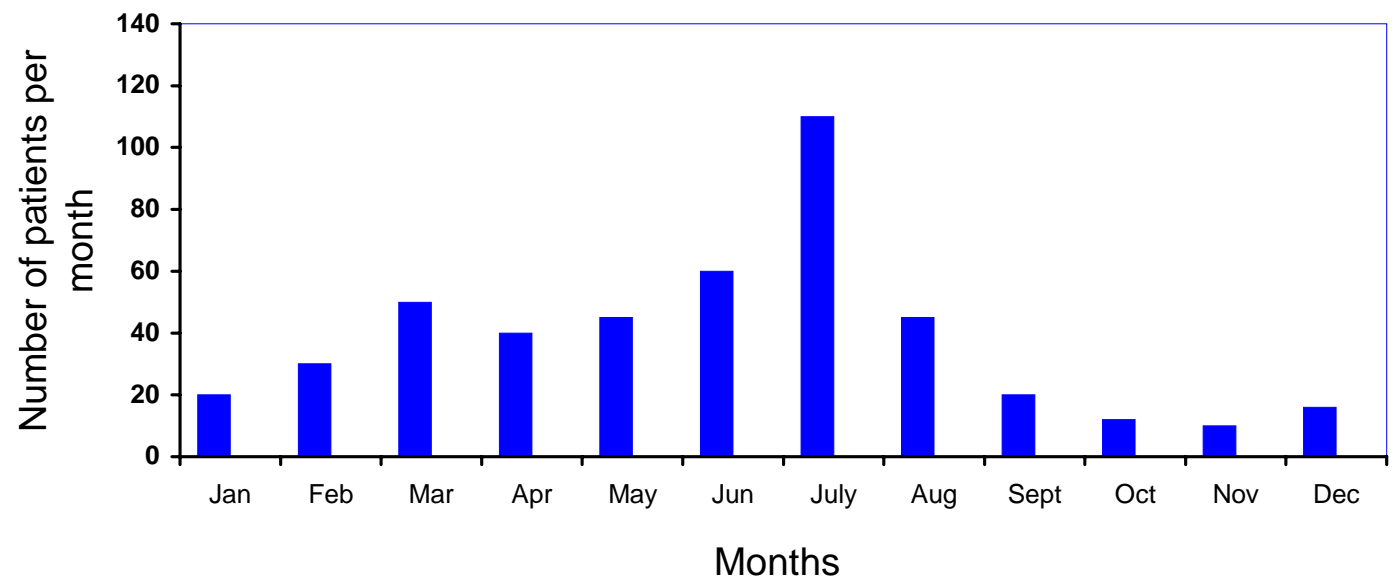

Figure 1: Seasonal variation of children with ITP

Table I: Management of children with ITP at two teaching hospitals

\begin{tabular}{lcccc}
\hline Name of institution & No treatment (\%) & IVIG (\%) & Corticosteroids (\%) & IVIG + Corticosteroids (\%) \\
\hline BSMMU & $28(25.45 \%)$ & $5(4.54 \%)$ & $47(42.73 \%)$ & $4(3.64 \%)$ \\
BICH & $7(6.36 \%)$ & $4(3.64 \%)$ & $13(11.82 \%)$ & $2(1.81 \%)$ \\
\hline Total & $35(31.82 \%)$ & $9(8.18 \%)$ & $60(54.55 \%)$ & $6(5.45 \%)$ \\
\hline
\end{tabular}

\section{Discussion}

Age distribution with a peak occurrence between 1 to 6 years; a study performed by Lusher et al., ${ }^{17}$, reported platelet count below $20 \times 10^{9} / \mathrm{L}$ and most of the children returned back to normal with or without drugs therapy. But in this study, peak age was found between 1 to 5 years with mean initial platelet count of $65.5 \times 10^{9} / \mathrm{L}$ and most of the children 60 responded to corticosteroids and 35 patient did not required any treatment. Most of ITP was observed in summer and lowest in winter. Sex distribution with a higher number of boys an observation of Kuhne et al. ${ }^{18}$ and another study done by Robb et al. ${ }^{19}$. In our observation, male child with ITP was also predominant.

Isolated thrombocytopenia not an usual indication for obtaining a bone marrow aspirate, two separate study performed by Dubansky et al., ${ }^{20}$ and Calpin et al., ${ }^{5}$ but if unusual findings of ITP are present or if corticosteroids are think of as initial therapy, a bone marrow aspirate is normally advised ${ }^{8,11,12,21}$. In this study the bone marrow aspiration and its morphology was obtained in each ITP patient to exclude the other hematological malignancies. 
Frequency of hospital admission in our observation do not reflects the recommendation by the American guidelines, which state that it is suitable for a child with severe life threatening bleeding regardless of the platelet count and for a child with a platelet count of less than $20 \times 10^{9} / \mathrm{L}$ observed by George et al., ${ }^{12}$. In contrast, our observation was that the child with ITP admitted with a mean platelet count of $65.5 \times 10^{9} / \mathrm{L}$ regardless of severe life threatening bleeding.

Outcome of children with ITP at 6 months appears not to be influenced by initial treatment schedule. This observation is consistent with the previously reported prospective trials ${ }^{22-24}$. In a retrospective study, 51 children with ITP did not receive any platelet enhancing treatment and only four patients received short-term corticosteroids because of extensive mucosal bleeding, reported by Diekernoff and Von Ruecker ${ }^{25}$. But in our study, 60 children initially was treated with corticosteroids, most of them received platelet count increasing treatment. Outcome was not similar to that of treated children with chronic ITP occurring in $27 \%$ of the patients and without previous life threatening bleeding. The high incidence of chronic ITP in our study subject might represent an error of under reporting of patients with rapidly resolving acute ITP at 6 months. Children who developed chronic ITP had higher initial platelet counts at diagnosis and were older than children with acute form. In contrast with the reports of George ${ }^{12}$, we did not report the increase number of girls than boys with chronic ITP.

ICH was found in 2 children with ITP, of whom $68.18 \%$ were treated which is far high the quoted incidence of $1 \%{ }^{12,26,27}$ suggesting a very high risk of this complication during the first 6 months after diagnosis. However, this result must be interpreted very carefully because of incomplete follow-up data and the probability that some patients with $\mathrm{ICH}$ at diagnosis might not have been recorded even if such patients reported to participating institutes.

In conclusion, it was observed that ITP has special fascination during summer season and the least in winter with mean initial platelet count of $65.5 \mathrm{x}$ $10^{9} / \mathrm{L}$ and the variable approaches to management of these admitted children at two teaching hospitals. Further multicenter prospective studies with large sample size are inevitable to find the clinical records on the morbidity related to bleeding manifestations.

\section{Acknowledgements}

We would like to express our grateful regards to all the pediatricians of the respective teaching hospitals who have sincerely submitted the data of their patients and the staffs of the laboratories of the respective hospitals who were engaged themselves to help us throughout this study.

\section{References}

1. Buchanan GR. The non-treatment of childhood idiopathic thrombocytopenic purpura. Eur J Pediatr. 1987; 146: 107-12.

2. McElfresh AE. Idiopathic thrombocytopenic purpura: To treat or not to treat? J Pediatr. 1975; 87: 160-61.

3. Buchanan GR, Alarcon PA, Feig SA. Acute idiopathic thrombocytopenic purpura management in childhood. Blood 1997; 89: 1464-65.

4. Lanzkowsky P. Disorders of platelets. In: Manual of pediatric hematology and oncology, $2^{\text {nd }}$ ed. Churchill Livingstone, New York. 1995, pp 185-238.

5. Calpin C, Dick P, Poon A, Feldman W. Is bone marrow aspiration needed in acute childhood idiopathic thrombocytopenic purpura to rule out leukemia? Arch Pediatr Adolesc Med. 1998; 152: 345-47.

6. Buchanan GR. Childhood acute idiopathic thrombocytopenic purpura: How many tests and how much treatment required? J Pediatr. 1985; 106: 928-30.

7. McClure PD. Idiopathic thrombocytopenic purpura in children: Diagnosis and management. Pediatrics for the clinician. 1974, pp 68-74.

8. Halperin DS, Doyle JJ. Is bone marrow examination justified in idiopathic thrombocytopenic purpura? Am J Dis Child 1988; 142: 508-11.

9. Blanchette V, Imbach P, Andrew M, Adams M, Millan J, Wang E. Randomized trial of intravenous immunoglobulin G, intravenous anti-D and oral prednisone in childhood acute immune thrombocytopenic purpura. Lancet 1994; 344: 703-07.

10. Montgomery RR, Scott JP. Hemorrhagic and thrombotic diseases. In: Nelson textbook of pediatrics. Behrman RE, Kliegman RM, Jenson HB (eds), $16^{\text {th }}$ ed. Philadelphia, WB Saunders Company, 2000, pp 150425.

11. Eden OB, Lilleyman JS. Guidelines for management of idiopathic thrombocytopenic purpura: The British Pediatric Hematology Group. Arch Dis Child 1992; 67: 1056-58.

12. George JN, Woolf SH, Raskob GE. Idiopathic thrombocytopenic purpura: A practice guideline developed by explict methods for the American Society of Hematology. Blood 1996; 88: 3-40.

13. Bolton-Maggs PHB, Moon I. Assessment of UK practice for management of acute childhood idiopathic thrombocytopenic purpura against published guidelines. Lancet 1997; 350: 620-23.

14. Vesely S, Buchanan GR, Cohen A, Raskob G, George J. Self reported diagnostic and management strategies in childhood idiopathic thrombocytopenic purpura: Results of a survey of practicing pediatric 
hematology/oncology specialists. J Pediatr Hematol Oncol. 2000; 22: 55-61.

15. Jayabose A, Mahmoud M, Levendoglu TO. Corticosteroid prophylaxis for neurologic complications of intravenous immunoglobulin G therapy in childhood immune thrombocytopenic purpura. J Pediatr Hematol Oncol. 1999; 21: 514-17.

16. Gaines AR. Acute onset hemoglobinemia and/or hemoglobinuria and sequelae following Rho (D) immunoglobulin intravenous administration in immune thrombocytopenic purpura patients. Blood 2000; 95: 2523-29.

17. Lusher JM, Zuelzer WW. Idiopathic thrombocytopenic purpura in childhood. J Pediatr. 1966; 68: 971-79.

18. Kuhne T, Berchtold W, Be TV, Binh TV, Imbach P. Ethnicity and environment may affect the phenotype of immune thrombocytopenic purpura in children. Pediatr Res. 2000; 48: 374-79.

19. Robb LG, Tiedeman K. Idiopathic thrombocytopenic purpura: Predictors of chronic disease. Arch Dis Child 1990; 65: 502-06.

20. Dubansky AS, Boyett JM, Falletta J. Isolated thrombocytopenia in children with acute lymphoblastic leukemia: A rare event in a Pediatric Oncology Group Study. Pediatrics 1989; 84: 1068-71.

21. Reid MM. Bone marrow examination before steroids in thrombocytopenic purpura or arthritis. Acta Pediatr. 1992; 81: 1052-53.
22. Sartorius JA. Steroid treatment of idiopathic thrombocytopenic purpura in children: Preliminary results of a randomized cooperative study. Am J Pediatr Hematol Oncol. 1984; 6: 165-69.

23. Buchanan GR, Holtkamp CA. Prednisone therapy for children with newly diagnosed idiopathic thrombocytopenic purpura: A randomized clinical trial. Am J Pediatr Hematol Oncol. 1984; 6: 355-61.

24. Blanchette VS, Luke B, Andrew M. A prospective, randomized trial of high-dose intravenous immunoglobulin $\mathrm{G}$ therapy, oral prednisone therapy and no therapy in childhood acute immune thrombocytopenic purpura. J Pediatr. 1990; 125: 98995.

25. Diekernoff R, Von Ruecker A. The clinical course of immune thrombocytopenic purpura in children who did not receive intravenous immunoglobulins or sustained prednisone treatment. J Pediatr. 2000; 137: 629-32.

26. Aronis S, Platokouki H, Mitsiki A, Haidus S, Constantopoulos A. Seventeen years of experience with chronic idiopathic thrombocytopenic purpura in childhood. Pediatr Hematol Oncol. 1994; 11: 487-98.

27. Blanchette VS, Turner C. Treatment of acute idiopathic thrombocytopenic purpura. J Pediatr. 1985; 108: 32627. 